\title{
Nash versus Schelling? The importance of constraints in legislative bargaining
}

\author{
STEFANIE BAILER AND GERALD SCHNEIDER
}

\section{I INTRODUCTION}

When the Council of Ministers had to decide on the so-called chocolate directive in 1999, its plan to allow vegetable fat in the production of candy products met with fierce opposition from Belgium, France, and the Netherlands. These three member states objected to the usage of vegetable fats other than cocoa in chocolate. Although they advanced some consumer-friendly arguments, continental manufacturers also tried to avoid competition from the British chocolate industry and to protect some of their traditional trading partners in the African, Caribbean and Pacific (ACP) countries. ${ }^{\text {I }}$ They particularly protested against the proposed derogations that would have allowed the United Kingdom and Ireland to continue the production of 'household milk chocolate', which contains a large amount of milk. While the Belgian government spoke of 'à la carte harmonisation' benefiting 'the industries of only certain

We would like to thank the editors, reviewers and seminar participants at the universities of Twente and Mannheim as well at the Netherlands Institute for Advanced Study (NIAS) meetings for their comments. Research support by the German Research Foundation is gratefully acknowledged. We received valuable assistance throughout the research process from Stefanie Börst, Simone Burkhart, Helen Callaghan, Han Dorussen, Dietrich Drüner, Daniel Finke, Nikolaus Hautsch, Stefan Klotz and Nadine Warmuth. The detailed and encouraging comments by the two chapter reviewersSimon Hug and Robert Pahre-greatly improved our theoretical argument and empirical analysis. While this article focuses on the accuracy of two-level game predictions, Schneider et al (2004) also consider other bargaining models and offer a more detailed discussion of the substantive implications.

I This became particularly obvious in statements by the Belgian, French and Luxembourg delegations after the last vote was cast in the Council in May 2000. Press release: Brussels (25 May 2000), Press: I 80 No. 8829/2/00, 2265th Council Meeting Internal Market, 25 May 2000. 
member states' (Europe Daily Bulletins, No. 7583, 29 October 1999), French chocolate makers demonstrated against the measure during the plenary session of the European Parliament in January 2000. The massive lobbying by the Belgian and French interest groups was, however, only partially successful. The European Parliament accepted the common position of the Council, allowing some sorts of vegetable fats in chocolate as well as the derogations favouring British and Irish 'family milk chocolate'. The legislature nevertheless added a 'fair trade' requirement. This successful amendment granted the industry the right to sell chocolate containing up to six sorts of vegetable fat everywhere in the European Union, as long as these ingredients came from developing countries (Europe Daily Bulletins, No. 7677, I6 March 2000).

The compromise found illustrates that domestic interests considerably shape the negotiation mandates of member states. At a theoretical level, the influence of sectoral interests in the negotiations on the chocolate directive is in line with the conjecture that domestically constrained and therefore supposedly weak negotiators, like the Belgian and French ministers under pressure from the chocolate industry and development countries, often possess disproportionate bargaining power. These two countries were able to postpone the directive for many years. Thomas Schelling (I960: 22) enthroned this hypothesis with the status of a 'paradox' and suggested that a commitment to a demanding negotiation position might be a useful bargaining device. He wrote, 'that the power to constrain an adversary may depend on the power to bind oneself; that, in bargaining, weakness is often strength, freedom may be freedom to capitulate, and to burn bridges behind one may suffice to undo an opponent.'

Although the strategic analysis of such commitment tactics did not really take off until the early I990s, Schelling's 'paradox of weakness' has enjoyed considerable popularity in descriptive and normative bargaining theory. Robert D. Putnam's (1988) influential article on 'twolevel games' reinforced the status of the counter-intuitive conjecture. According to him, constrained governments might try to exploit their constraint to advance their own interests. It was especially this idea that has encouraged empiricists and formal modellers to dwell on the 'paradox of weakness'.

This chapter evaluates the empirical relevance of the Schelling conjecture, showing that two-level game models do not predict much better than standard models of multilateral bargaining. We embed the Schelling conjecture within a conventional multi-actor Nash bargaining game. 
Our assessment of the 'paradox of weakness' relies on different criteria to account for the possible influence that domestic institutions, diverging ideological stances, and the behaviour of the negotiators exert on the final outcome. We compare the predictive power of the different Schelling bargaining games with the accuracy of the symmetric Nash bargaining game. Our results show that the model that simultaneously considers institutional and ideological constraints fares the best by comparison. The models that try to measure domestic constraints through ideological constraints alone or the occurrence of threats have, by contrast, a rather low predictive accuracy. The chapter is structured as follows: We first introduce the Schelling conjecture and embed it within a multiactor Nash bargaining model. Next, we outline our research design. The empirical section presents the model comparison and analyses the conditions under which the assumption of domestically constrained governments makes sense in the analysis of EU decision-making.

\subsection{BARGAINING WITH DOMESTICALLY CONSTRAINED ACTORS: THE BASELINE MODEL}

Most introductions to the literature on international negotiations describe bargaining as both a cooperative and a conflictive endeavour in which negotiators share an interest in solving a common problem, but disagree on the appropriate settlement (e.g. Wagner 2004). Since no formal bargaining protocol exists for most international negotiations, government leaders possess ample possibilities to influence the outcome through strategic means. This implies that formal power considerations or, to put it more bluntly, the international pecking order does not suffice to understand the final allocation of resources among the negotiators. While psychological research most often focuses on the varying ability of individual negotiators to strike a deal, political scientists and economists believe that such advantages will cancel out on average. In their view, the deal that the negotiators probably strike is, by and large, a consequence of the varying bargaining constraints and the way in which the negotiators manipulate them.

One important and non-trivial generalisation in this vein is the 'paradox of weakness'. With this metaphor, Schelling (r960: 24, italics suppressed) describes a manoeuvre whereby one side 'can accept the irrevocable commitment in a way that is unambiguously visible' to the other. Through this commitment tactic the first negotiator can 'squeeze the range of indeterminacy down to the point most favourable to him'. 
The credibility of a commitment thereby often depends on the possibility of manipulating one's own constituents, 'If a binding public opinion can be cultivated and made evident to the other side, the initial position can thereby be made visibly final" (Schelling I960: 28). In other words, international negotiators who have to seek the ratification approval of a conservative audience back home can credibly threaten that the negotiations will fail unless they receive some concession to appease their principal. Fearon (1994) as well as Schneider and Cederman (1994) have taken up this argument and formally shown how the costs of commiting oneself domestically to a particular negotiation position (socalled audience costs) can influence international bargaining outcomes.

Although Schelling in his informal discussion also listed some limitations to this tactic, the conventional wisdom was soon reduced to the deterministic hypothesis that the constrained side almost always possesses a bargaining advantage. An influential manifestation of this trend was Putnam's (1988; 1993) article on 'two-level games', in which he tried to establish the Schelling conjecture as an empirical law of international negotiations:

'The larger the perceived win-set of a negotiator, the more he can be 'pushed around' by the other Level I negotiators. Conversely, a small domestic win-set can be a bargaining advantage: 'I'd like to accept your proposal, but I could never get it accepted at home'. (Putnam I993: 44I)

With the two-level game approach, Putnam tried to overcome a lacuna that he had identified in the theory of international relations. In his view, both the 'liberal' and 'realist' research traditions in international relations unnecessarily reduce the interaction between the international system and the nation state to a one-way street. ${ }^{2} \mathrm{He}$ claims rather that his two-level game approach provides a conceptual framework for building 'general equilibrium' theories that pay systematic attention to the possibility of reciprocal causation. Although Putnam (I988: 435) only sketched his conjectures, his call for a more rigorous 'algebra' of the nexus between domestic and international politics did not remain unheard. Yet, Putnam's popularisation has mainly triggered off sophisticated formal work and isolated case studies whose implications are hard to generalise. Some 15 years of intellectual investment in the two-level

\footnotetext{
2 Moravcsik terms Putnam's approach 'interactive', to distinguish it from 'additive' approaches in which the two sets of constraints-domestic interests and international bargaining_are treated as superimposed (Moravcsik I993: I7).
} 
game approach have, in short, led to the typical mismatch between theoretical ambition and empirical confirmation that unfortunately still characterises many subfields in political science. Although a multitude of models probe the limitations of the 'paradox of weakness', only a very limited number of studies explores the empirical relevance of the Schelling conjecture in a systematic fashion.

Most formal models examine how domestic constraints shape international interactions. ${ }^{3}$ The consensus is that the Schelling conjecture has to be qualified. Yet, this agreement does not reach much beyond the sober assessment that much of the early excitement about the 'paradox of weakness', and especially the two-level game metaphor, was not warranted. Iida (I993), Schneider and Cederman (1994), Mo (1995) and Tarar (200I) show situations in which negotiators benefit from domestic constraints. But they all condition the conjecture in one way or the other. One implication of this work is, for instance, that negotiations risk breaking down if the non-constrained governments are not well-informed about the constraint of the other side.

Milner (1997; see also Milner and Rosendorff 1996, 1997) as well as Hammond and Prins (1999), by contrast, argue that the Schelling conjecture is most often not true. In the view of Milner (1997), negotiators suffer rather than profit under domestic constraints. Hammond and Prins (I999) examine all possible preference configurations and conclude that the 'paradox of weakness' may be practically irrelevant. Martin (2000) argues in a similar vein that opposing legislatures may make cooperation between states easier on some occasions, because they render a commitment more credible. Yet, the positive impact of the legislature depends on the utility of the reference point. As Pahre (200I) points out, a conservative legislature is willing to go along with international agreements when the distance between its ideal point and the one of its government grows.

We believe that several modelling assumptions have sharpened the disagreements over the Schelling conjecture. A first important difference in the models is the attribution of agenda setting power. Milner (I997), and Milner and Rosendorff (1996; I997), for instance, 'translate' the Nash bargaining solution into a spatial setting by introducing a direct distance utility measure. This produces a corner solution with the effect that the actor closest to the status quo controls the bargaining protocol

3 Lohmann (1997) is one of the few studies that rigorously examines the impact of international bargaining on domestic politics. For ratification games see also Schneider and Weitsman (I996) and Hug (2002). 
(Butler 2004). It follows quite naturally in a situation of complete information that domestic constraints would hurt this actor, because they prevent the negotiating governments from 'agreeing' on the agenda setter's ideal point. ${ }^{4}$ Hammond and Prins (1999) are able to overcome the arbitrariness of endowing one actor with the agenda setter power by placing a possible outcome within a much larger bargaining set. Their exhaustive analysis of all preference configurations points out the possible exceptionality of situations in which negotiating governments can profitably use domestic constraints. This conclusion, however, crucially hinges on the assumption that the different preference configurations are uniformly distributed. Because we do not know how likely certain profiles are, we are not able to firmly reject the Schelling conjecture, but might have to concede that it depends on certain preference configurations. A second difference between the models is the interpretation of what constitutes the fall-back position in international negotiations, and which actors control it. Pahre (200I) convincingly argues that two-level game applications should focus on the reversion point, and thus the outcome that would result in the case of a negotiation failure. He also demonstrates that the model implications become ambiguous if either the government or the opposition is allowed to control the reversion point.

A third assumption, which crucially affects the scope of some theoretical claims, refers to the information level of the actors under consideration. The spatial exploration presented by Hammond and Prins (I999), for instance, excludes the possibility that informational asymmetries lend a particular claim credibility. In the descriptive literature on two-level games, Moravcsik (I993: I 59) similarly maintains that a negotiator is only seldom able to bluff that a domestic constraint is binding. In his view, the other governments might be able to predict the actions of the cheater, '. . a among modern information-rich democracies, it is extremely difficult for negotiators to mask their true domestic win-set, even in a sensitive area of national security like weapons procurement'. ${ }^{5}$

\footnotetext{
4 Note that this assumption is not necessary and that a quadratic transformation would not result in endowing one specific actor with the agenda-setting power (Butler 2004). For a controversial discussion about other aspects of this model, see the exchange between Dai (2002) and Mansfield et al (2002) that the Mansfield et al (2000) extension of the Milner/Rosendorff model provoked.

5 In his assessment of the evidence assembled by the contributors to Putnam (I993), Evans and Jacobsen, Evans (I993: 409) states that leaders 'did try to strategically misrepresent their own polities, but not as often as expected, and with much less success'.
} 
However, to assume informational asymmetries away borders on a hapless attempt to throw the baby out with the bathwater: why should fully-informed negotiators bother to bargain at all, instead of agreeing on the supposedly easily foreseeable bargaining outcome in the first place?

Differences between models, such as the ones we discussed here, are partly necessary because of varying ambitions and applications. But we believe that some of the judgments made on the validity of the Schelling conjecture depend too much on the implicit and explicit assumptions that guide the theoretical work. We consequently believe that the debate on the relevance of the 'paradox of weakness' is far from being settled.

This inconclusiveness also explains why the literature on two-level games is still growing. This holds particularly true for the application to the European Union which has traditionally been one of the main testing grounds for the Schelling conjecture. Schneider and Cederman (I994), Schneider (1994), Bräuninger et al (200I), and Hug and König (2002) explore how real or feigned constraints affect the negotiation outcome in the purely intergovernmental context of European Council deliberations. Schneider and Weitsman (1996), Hug and Christin (2002), and Hug (2002) examine how the government tries to convince domestic constituents in referendum debates, while König and Hug (2000) focus on ratification in the parliamentary setting.

The frameworks used in these studies are, however, not directly applicable to an analysis of European Union legislation. One key reason for this limitation is obviously that these applications of the two-level literature focus on the intergovernmental arena, be it the bargaining rounds in the European Council or the ratification of treaty amendments, while our cases are drawn from the legislative rather than the constitutional arena. Because we examine day-to-day decision-making rather than the grand bargains in this article, we need to consider how domestic actors, and especially the national parliaments, condition the negotiation mandates of their governments. In a pioneering study, Martin (2000: I68) lists three factors that increase the credibility of a state's commitment to a particular bargaining position. First, in her view, early parliamentary involvement in the negotiation process reduces parliamentary opposition toward an international bargain. Second, ministers are more likely to negotiate well if they are accountable to the parliament. Third, a government is more likely to be taken seriously if the implementation is transparent and the actors who are involved in this decision-making phase are identifiable. 
However, not all parliamentary oversight mechanisms will directly affect government behaviour as in the US system where the executive is not formed out of the legislative parliamentary bodies. According to Pahre (1997: I48), domestic constraints may only matter if the scrutinising committee also includes members of the opposition parties.

Models that treat executive preferences as exogenous are appropriate for a directly elected executive but exclude the government formation problem that is central to parliamentary government.

This is the main reason why we focus in this examination on the possible influence that powerful and ideologically independent legislatures are able to exert on government negotiation behaviour. We embed our analysis of two-level bargaining games within the parsimonious framework that the Nash bargaining solution (NBS) offers. The NBS stands for an axiomatic approach to bargaining that finds widespread application throughout the social sciences. Several reasons justify the reliance on this static approach. First, we can extend the NBS, which Nash (I950) originally developed for the analysis of bilateral negotiations, to the analysis of multilateral bargaining situations. Non-cooperative bargaining models, by contrast, can only be extended to a multi-actor world on the assumption that the actors adhere to a strict bargaining protocol, or that the size of the pie alters stochastically over the bargaining rounds (Merlo and Wilson 1995). Yet, in the European Union and especially within its most important legislative actor, the Council of Ministers, the rules that guide the interactions between the negotiators are so sparse and feeble that every commitment to a particular negotiation mode is incredible. Furthermore, many legislative negotiations are guided by a shortened time horizon, rendering assumptions about multiround interactions tenuous. If we were using a non-cooperative framework, such as the signalling game used by Schneider and Cederman (I994), we would thus be forced to reduce the number of players to two or possibly three actors or to assign agenda setting power to one member state. Schneider et al (2004) test how relevant extensions of the Rubinstein sequential bargaining model (Baron and Ferejohn 1989; Merlo and Wilson 1995) are in comparison to the NBS. Yet, their application is still static, as they have to use the saliency measure of the DEU data set as a proxy for the time preference.

Our second motive for relying on a cooperative approach is empirical. To our regret, the DEU data set does not contain sufficient information on the dynamics that characterise the negotiations on the legislative 
proposals under consideration. To give full justice to a non-cooperative model, it would be essential to identify the sequence of moves. But even if we had this information, it would not be guaranteed that we could interpret it meaningfully. Interestingly, the spatial literature still disagrees on which institutional actor possesses agenda-setting power under certain legislative procedures and would thus be the first mover (see Steunenberg and Selck, chapter 3 of this volume). The only information that we possess on the behaviour of the negotiators - whether or not an actor issued a threat - will be used in one of the operationalisations of domestic constraints. A third and final reason why we rely on the NBS is its parsimony. The canonical version of this tool allows us to calculate point predictions by only including information on the preferences of all relevant actors. If one assumes like us that Ockham's razor is a useful yardstick to evaluate a model, the NBS possesses a major advantage over more baroque models of EU decision-making. ${ }^{6}$

Technically, the NBS maximises the product of the differences between the outcome and their so-called disagreement points. In our application, the reference point is the common disagreement point of the actors. Binmore (1998: 66) criticises that applications in industrial relations often equate the status quo with the disagreement point, although the status quo might not necessarily coincide with the outcome that is realised in the case of a bargaining failure. We follow this line of logic and assume that the reference points represent the common fallback position of the actors.

If the actors are domestically constrained, their disagreement point is assumed to be closer to their ideal point than the reference point. In other words, we assume in line with the literature on two-level games that some governments are able to credibly restrict their bargaining zone (or 'win set', as Putnam put it in reference to spatial models of legislative choice). In the logic followed here, it is always profitable to be constrained because the distance between the ideal point and the disagreement value shrinks.

Note that we assume in contrast to some existing limited information applications (e.g. Iida I993; Schneider and Cederman 1994) that a domestic constraint is always credible. Although the assumption of perfect credibility is certainly unrealistic, it is in accordance with some of the contributions to the literature on two-level games discussed above.

${ }^{6}$ For an early application of the NBS to the EU decision-making see König (I997). 
More importantly, our focus is empirical, and we will explore the relative importance of the Schelling conjecture by comparing the average predictive power of the NBS without constraints to several extensions of the NBS in which some actors are supposed to be domestically constrained. This gives us some leverage to decide whether the Schelling conjecture is relevant in contrast to the standard bargaining tool of cooperative game theory. Our evaluation will also help us decide which domestic factors contribute to the bargaining leverage of EU actors.

We assume in line with the literature that the set of Pareto-improving outcomes $\Theta$ is non-empty. If the bargaining space contains the outcome and the disagreement value, the NBS amounts to the following maximisation problem for negotiations among $n$ players.

$$
\max _{O \in \Theta} \prod_{a=1}^{n}\left(u_{a}(O)-u_{a}(Q)\right)
$$

where $O$ is the predicted bargaining outcome and $Q$ the reference point. ${ }^{7}$ In this and the following equation, the subscript $n$ stands for players, $i$ for issues. We add to the standard NBS setup the distance between the actor's ideal point and the final negotiation outcome. We assume that the further away a bargaining outcome $x$ is from the bliss point $x_{i a}$ from each player, the larger the utility loss. If we use Euclidian distances to calculate these utility changes, the NBS amounts to the following:

$$
\max _{\mathrm{O} \in \Theta} \prod_{a=1}^{n}\left(-\sqrt{\left(\mathrm{O}_{i}-x_{i a}\right)^{2}}+\sqrt{\left(Q_{i a}-x_{i a}\right)^{2}}\right)
$$

Our issue-per-issue calculations of the NBS are based on equation 6.2. ${ }^{8}$ Because the canonical version of the NBS does not consider power differentials among negotiators, we only have to know the outcomes the actors favour the most and the location of the reference points. ${ }^{9}$ We use the symmetric NBS as the baseline model and compare its relative predictive power against three different interpretations of the two-level game. The first two-level variation of the NBS refers to a situation in which a government faces a powerful European affairs committee, while the second measures the interaction effect between this institutional

7 Muthoo (I999) offers a recent introduction to the Nash bargaining solution and other standard tools in negotiation analysis.

8 The calculation of the NBS at the level of the proposal and at the level of each issue coincide as long as the utility of a proposal has a multiplicative form and the actors attribute equal weight to the issues.

9 Bailer and Schneider (2002) evaluate whether or not differences in the capabilities of the actors are important. 
variable and the occurrence of a preference divergence between the government and its European Affairs Committee. The third definition of a constraint is more behavioural and considers the impact that the threat of an actor has on the bargaining outcome.

\subsection{RESEARCH DESIGN}

In this section we outline how we operationalised the key variables and how we implemented the four permutations of the Nash bargaining solution. We use different measures to operationalise domestic constraints because the literature stresses either institutions, preferences or threats as the key resources on which governments rely in international bargaining processes (Bailer and Schneider 2002). This allows us to assess whether domestic constraints make a difference at all, and which of its components influence the average bargaining behaviour.

The first domestic constraint is purely institutional. To assess the power of the EU affairs committees, we quantify the four categories Bergman (1997) used in his comparative evaluation of these parliamentary institutions. The first consideration in our operationalisation is whether or not the EU affairs committee is involved in pillar I, II, and/ or III decisions of the Maastricht Treaty. The extent of involvement in the three pillars is in our view a direct indicator of committee influence. All national committees have a say in the Common Market Pillar, whereas only half of them have the possibility to give opinions on Justice and Home Affairs and the Common Foreign and Security Policy. This is, for instance, the case for the French EU committee.

The second criterion is whether the committee can submit the proposals under deliberation for plenary debate. This right grants parliamentarians the opportunity to open the debate on issues that otherwise could pass without notice by the public. The Swedish EU affairs committee is the most restricted in this sense and has no right to bring topics to the plenary fore. All other EU-committees, however, may do so.

A third criterion assesses the degree to which the opinions of the committee bind the government. To develop this scrutiny measure, Bergman assigned the EU countries to three categories. A committee exerts little influence if it can only exchange information with its government and if the executive side can easily ignore the advice of the legislative body (e.g. Greece, Ireland, Italy, Portugal, Spain). Moderate forms of influence exist when the government follows the opinion of the committee (e.g. Finland, Sweden). A high level of influence is characteristic of a 
situation in which the committee is able to make binding recommendations (e.g. Austria, Denmark, Germany).

We measured the different subcategories on ordinal and dummy scales and created an additive index of these powers. ${ }^{\circ}$ We considered an additive index useful because the three criteria represent different facets of the relationship between the executive and the domestic legislature. A committee can for example be powerful if it submits issues to the parliament and has a say in all three Community pillars even if it does not include Members of European Parliament (MEPs) in its meetings.

To make our NBS calculations more transparent, we only consider four degrees to which European affairs committees are able to reduce the zone of agreement of their negotiating government. The institutional constraint is large if the additive index exceeds six points. This is the case for Austria and Denmark. We consider a constraint to be above the average if the additive index amounted to five (Finland, Germany). We coded an institutional constraint as average in the event that the additive index equalled four (Ireland, the Netherlands, Sweden, Luxembourg), and a government is not institutionally constrained in its negotiation behaviour if the index ranged between zero and three (Belgium, France, Greece, Italy, Portugal, Spain, United Kingdom). Operationally, we reduced the bargaining range and moved the disagreement point closer to the ideal point if an actor is institutionally constrained. We reduced the bargaining zone by 75 per cent for highly constrained, 50 per cent for member states with an above-average constraint and 25 per cent for an actor with an average constraint.

The second operationalisation of domestic constraints builds on this indicator and adds the possibility of a preference divergence between the government and the domestic legislative committee to it. Relying on the index developed by Hix and Lord (I997), we identified the ideological

Io Degree of bindingness of EU affairs committees: a case receives the scale weight 2 if the degree of bindingness is strong, while it obtains a scale weight of I if the corresponding value is moderate. A value of $\circ$ finally results if the degree of bindingness is low. Plena: this category is coded as I if the EU affairs committee has the opportunity to submit issues under deliberation to the floor for plenary debates. A case gets the scale weight $\circ$ if this is not allowed. Pillar: a country receives the value of 3 if its EU affairs committee is involved in debates on pillar I, II, or III. The category 2 refers to cases where the committees are only allowed to participate in pillar I and II decisions, while a value of I corresponds to partaking in pillar I only. The zero code is reserved for countries in which the committees are not allowed to participate in the deliberations on any decisions within one of the three Maastricht pillars. 
position of the cabinet and committee members on a left-right scale by subtracting the mean of the party positions of the members in the national cabinet from the mean of the party positions of the members in the EU committee. ${ }^{\mathrm{II}}$ We obtained the second constraint measure by multiplying the absolute value of these distances with the ideological constraint and by reducing the variance to three categories: no constraint (range of values O-I.9), average constraint (2.0-3.9), large constraint (4.0-7.5). If a member state fell into the last category, we reduced the bargaining zone 66 per cent (Belgium, Germany, Sweden, Finland, Luxembourg). A reduction of 33 per cent was made in case of an average constraint (Italy, Greece, France, Spain, Austria). No changes were made if there was no constraint (the Netherlands, United Kingdom, Ireland, Denmark, Portugal). We acknowledge that our preference measure is rather crude. However, the left-right dimension is the dominant cleavage in the European Parliament (Noury 2002), and we therefore have some reason to assume that it is also important in the Council of Ministers (Zimmer et al 2005). Since the delegations of the member states in the Council are formed by the national representatives of ministries which makes them directly dependent on the executives and their respective party orientation, we consider party profiles as valid variables to estimate the political orientation of the negotiating actors.

The third and final operationalisation of domestic constraints is purely behavioural and relies on the usage of threats by a member state government. Information on threats was also obtained in the DEU interviews. The theoretical rationale for using this indicator is the expectation that domestically constrained actors are more likely to signal their commitment to a specific solution than other negotiators. We admit that threats are relatively rare events and that only governments whose credibility is reduced will utter them. We are only able to report threats that were put forward openly enough for our interview partners to notice, even if they were not from the party of the threatening or the threatened side. It was not possible to take into account all possible bilateral threats issued on an informal basis. We also acknowledge that experts responded very differently to our question of whether or not they were able to observe threats.

II Austria (0.4), Belgium (-2.4), Denmark (0.32), Finland (-I.5), France (-I.7), Germany (-I.05), Greece (-I.4), Ireland (0.2), Italy (I.3), Luxembourg (I.82), the Netherlands (-0.2), Portugal (-0.43), Spain (I.96), Sweden (-1.95), United Kingdom (0.93). Hix and Lord (1997) use mainly the data developed in Huber and Inglehart (I995) and fill in values for countries not covered by Huber and Inglehart with data from Mavgordatos (1984) and other sources. 
While some interview partners completely negated the existence of such stratagems, others claimed that there are so many implicit or secret threats and promises going on between the I 5 delegations, that they could not even be reliably counted. Nevertheless, we have data on 23 explicit threats that occurred during the negotiations. ${ }^{\mathrm{I2}}$ We asked for the intensity of threats during the interviews and measured them with three categories: low (no reduction of the bargaining space), average (reduction of 33 per cent), high (reduction of 66 per cent).

We used the library constrained optimisation of GAUSS, the programming language, in order to optimise our function and to constrain our result to the bargaining space between $\circ$ and Ioo. ${ }^{13}$ We assumed that the reference point lies at the position 0 . The reference point was already at this position in $\mathrm{IO}_{4}$ of $\mathrm{I} 62$ issues. If $\mathrm{O}<Q<\mathrm{IOO}$, we calculated the absolute distance of the actors from the reference point. We used the position of the Commission as a substitute for those cases in which the interview partners were not able to identify a common reference point. Although this might appear to be a considerable assumption, we consider it justified if one considers the Commission's initial position as the point from which the discussion started. In some situations, there were I 5 different national situations since there had been no EU legislation in this policy field before. As we are not able to identify these I 5 reference points, we work with the crude approximation of the Commission position as reference point. Similarly, if the rare event occurred that there was no Commission position, we filled the reference point in at that place.

The Newton algorithm served as our optimisation method. We employed the mean as the starting vector in all models. The mean was calculated from all positions of the member states and the Commission in the case of proposals under the consultation procedure and all member states, the Commission and the European Parliament in the case of proposals under the co-decision procedure. Table 6.I summarises the models, the parameters used, and the implicit modelling assumptions.

We imputed the positions of actors whose positions are missing in the data set because the experts stated they were indifferent. We located these actors half way between the reference point and the position of the

${ }^{\text {I2 }}$ On 23 occasions an actor formulated a threat towards his or her counterparts. As we measured threats only at the proposal level, these 23 threats are spread over 30 issues.

${ }^{3}$ The source code used for calculating the model predictions is available at the homepage of the second author (www.uni-konstanz.de/FuF/Verwiss/GSchneider/). 
Table 6.I. Models, parameters and assumptions

\begin{tabular}{|c|c|c|}
\hline Model & Variables & Assumptions \\
\hline $\begin{array}{l}\text { Symmetrical NBS } \\
\text { (NBS) }\end{array}$ & Preferences & $\begin{array}{l}\text { All bargaining models: } \\
\text { - starting vectors for }\end{array}$ \\
\hline $\begin{array}{l}\text { Two-level } \\
\text { symmetrical NBS } \\
\text { (institutional } \\
\text { constraints) (NBS } \\
\text { Two1) }\end{array}$ & $\begin{array}{l}\text { Preferences, power } \\
\text { of EU affairs } \\
\text { committee }\end{array}$ & $\begin{array}{l}\text { all calculations: mean } \\
\text { - optimisation method: } \\
\text { Newton } \\
\text { - procedure: constrained }\end{array}$ \\
\hline $\begin{array}{l}\text { Two-level } \\
\text { symmetrical NBS } \\
\text { (interaction } \\
\text { model) (NBS } \\
\text { Two2) }\end{array}$ & $\begin{array}{l}\text { Preferences, } \\
\text { institutional } \\
\text { constraints, } \\
\text { preferences of EU } \\
\text { affairs committees }\end{array}$ & $\begin{array}{l}\text { optimisation (calculated } \\
\text { in GAUSS, library co.src) }\end{array}$ \\
\hline $\begin{array}{l}\text { Behavioural model } \\
\text { (threats) }\end{array}$ & $\begin{array}{l}\text { Preferences, threats, } \\
\text { intensity of threat }\end{array}$ & \\
\hline
\end{tabular}

Commission. This indicates that these delegates simply did not care whether the status quo or the Commission proposal would result from the negotiation. As the NBS is static, our model does not take any agenda setter considerations into account. ${ }^{14}$ Actors were included in our calculations, even if they were at risk of being made worse off by the decision outcome in comparison to the status quo. Although such players could be treated as inessential, we assume that they are trying to minimise their utility loss.

\subsection{THE CHOCOLATE DiRECTIVE AS AN ILLUSTRATION}

We illustrate the predictions of our models with the decision on the chocolate directive. This internal market proposal gave rise to four controversial issues. The goal of this proposal was to create common rules for the composition, manufacturing, specification, packaging and labelling of cocoa and chocolate products. Because the chocolate industry in the member states followed different traditions, the main issue was the wish of the United Kingdom and Ireland to continue to use vegetable fats other than cocoa butter in the production of chocolate. Belgium and

I4 We did not include the position of the European Parliament for the consultation cases. 
the Netherlands voted against the common position while Luxembourg abstained.

The proposal had a long history. The Commission had already introduced its ambition to harmonise the rules that structure the chocolate market in the I970s. These intentions were, however, to no avail since the Belgian, French, Dutch and Luxembourgian diplomats successfully prevented vegetable fat chocolate from entering their national markets. The resistance of the candy protectionists had the effect that British chocolate was practically banned from the continent until the midI990s. The discriminated producers, especially the large, export-oriented manufacturer, Cadbury, had, however, a strong interest in entering the continental market. The cocoa coalition of the small chocolate producers in Belgium, France, the Netherlands and Luxembourg protested strongly against this sort of 'impure' chocolate. Yet, the opposing faction considered not only the interests of their own industry. The diplomats of these member states also tried to appease cacao producers in their former colonies, especially from Ivory Coast.

A related bone of contention was the question of how to label chocolate containing vegetable fat. The British delegates considered this issue nearly as important as the permission to use vegetable fats. This issue provided ample opportunity for the Belgians to block the directive by suggesting that chocolate containing vegetable fat should be labelled so that cocoa-fat chocolate would be easily recognised as 'quality chocolate'. French chocolate producers helpfully suggested that vegetable fat chocolate should receive the brand name 'végécao' (Europe Daily Bulletin, No. 7634, I 4 January 2000). The British, in return, objected that this label would amount to a severe trade barrier for their manufacturers.

An intensive discussion also arose over the derogation that the Commission wanted to grant to Great Britain and Ireland. In spite of its mission to guarantee common market rules, the Commission supported the idea of extending an existing derogation to allow the British and Irish industry to produce chocolate with a higher milk content than stipulated for the fabrication of regular chocolate. This exemption was important for the two member states because a complete harmonisation might have affected the production of the popular 'Cadbury's dairy milk'. The expert whom we interviewed on that proposal pointed out that the British delegates would have even been prepared to block other legislation in order to receive this exception. In the end, the other delegations accepted the labelling of the British chocolate as 'family milk chocolate' and granted the derogation. This compromise constituted, at least in the eyes 
of our interview partner, a major surprise. The new label could potentially make the British chocolate more attractive than the Belgian or French milk chocolate.

The final outcome, which also found the support of the European Parliament, allows the use of vegetable fat up to five per cent and the sale of egetable fat chocolate everywhere in the European Union. Yet, it simultaneously grants continental producers the right to label cocoa-fat chocolate with 'pure cocoa' or 'guaranteed traditional specialty', and requires that vegetable fats are denoted close to the list of ingredients. Furthermore, the delegations agreed on six tropical vegetable fats such as palm oil which are from now on to be used in vegetable fat chocolate, in order to soften the negative effects for developing countries.

The key member states in the legislative negotiations were the United Kingdom, Belgium, Luxembourg, the Netherlands and France. The institutional constraints of these states are average to low. The institutionalideological constraint category indicates a high restriction for Belgium and Luxembourg, an average restriction for France and no restrictions for the Netherlands and the UK. Judging from these measures alone, we would expect the more constrained states to be more successful. Empirically, however, this does not apply to the British negotiators, who were rather successful. The highly constrained negotiators from Belgium and Luxembourg, conversely, had to make considerable concessions.

Interestingly, the member states for which legislation in this domain was important experienced all considerable pressure from interest groups: Cadbury Limited had a strong interest in finally getting access to the continental market and lobbied the British government. Chocolate producers in Belgium and France feared this competition. They received support from cocoa-producers in the developing world, especially the Ivory Coast. Demonstrations of Fair Trade Associations in Brussels and 'chocolate tasting sessions' of a group of MEPs interested in consumer issues are examples of this pressure (Daily Bulletin, Agence Europe, Iо February I995).

Our expert identified four issues on which the stakeholders disagreed. Figure 6.I illustrates that the coalitions acted quite homogeneously across these topics. The member states are, however, relatively polarised on whether or not they should follow the Commission proposal, or the proposal favoured by the Benelux countries and most of the southern member states. Note that the Commission and the Parliament were initially divided over whether or not the United Kingdom and Ireland should obtain derogations. 
Issue 1: Fat content

\begin{tabular}{|c|c|c|c|c|}
\hline \multirow{2}{*}{$\begin{array}{l}\text { BE, EP, FR, EL, IT, } \\
\text { LU, NL, ES, Ref, } \\
\text { NBS Twol }\end{array}$} & & \multicolumn{2}{|c|}{ NBS Two2 } & \\
\hline & Outcome & NBS & COM, & $\begin{array}{l}\text { DK, AT, FI, DE, } \\
\text { IE, PT, SE, UK }\end{array}$ \\
\hline 0 & 50 & 94.6 & 97.99 & 100 \\
\hline $\begin{array}{l}\text { Position } 0 \text { : no vegetable fats in } \\
\text { chocolate other than cocoa }\end{array}$ & $\begin{array}{l}\text { Position 50: natural } \\
\text { vegetable fats only; ban on } \\
\text { synthetic fats }\end{array}$ & & vegeta & $\begin{array}{l}\text { Position 100: all } \\
\text { ble fats permitted }\end{array}$ \\
\hline
\end{tabular}

Issue 2: Labelling of chocolate

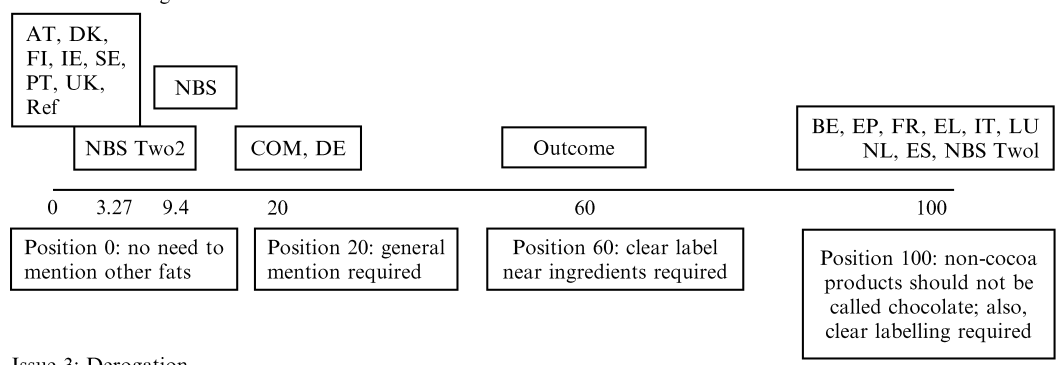

Issue 3: Derogation

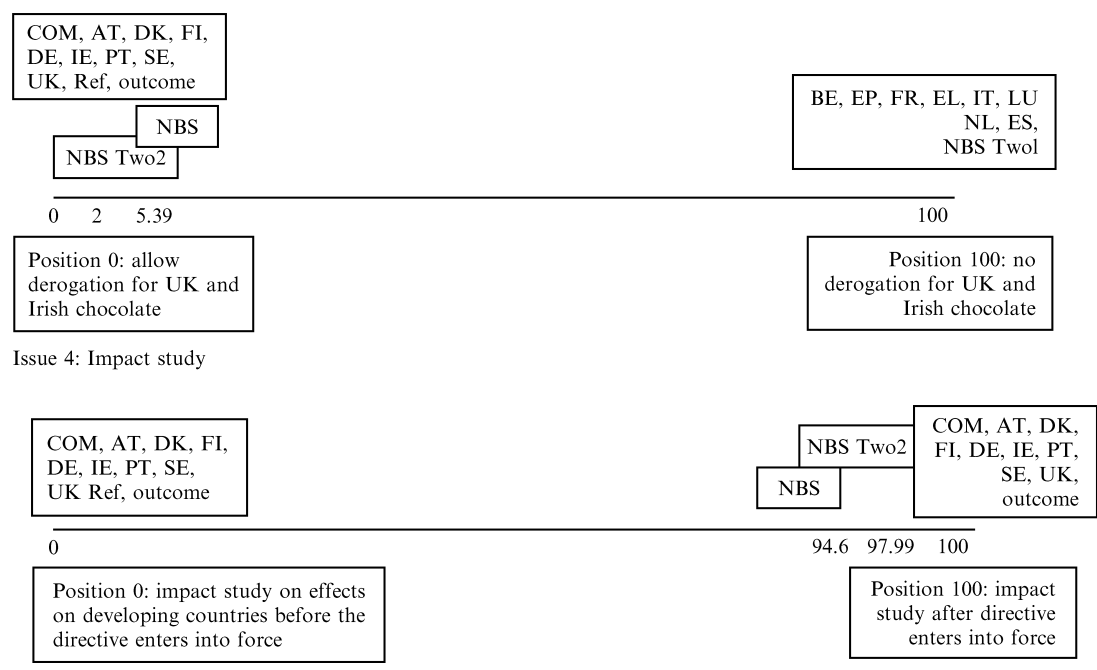

Figure 6.I. The negotiations over the chocolate directive ${ }^{a}$

${ }^{a}$ For details of the models NBS NBS Two1 and NBS Two2, see Table 6.1.

The bargain finally struck by the EU actors on the first two dimensions is a typical consensus both sides could live with. The decisions made on the two other issues is much more majoritarian by contrast. Overall, the northern camp, the Iberian states and the Commission are closer to the solution that the Council of Ministers adopted against the 
opposition of Belgium and France. These two member states appear to have been unsuccessful in finding sufficient support in the coalition often derogatorily called the 'club méditerranée'.

Figure 6.I shows that the predictive accuracy varies a lot across the issues. The preferences on all issues were rather polarised. The models typically predict outcomes that are close to the preferences of one of the leading coalitions. This explains why some of them predict rather well on issues three and four. When the decision-making process results in a compromise, the accuracy of all models conversely suffers. Interestingly, the Commission is part of both winning coalitions on issues three and four. This could indicate that the supranational agent possessed some sort of informal agenda setting possibilities in these contests, while it did not have a privileged position on the other issues.

The institutional model performs, relatively speaking, quite badly. This model, which only takes institutional constraints into account, has an error of 100 issue scale points on issues three and four. The more refined model that also takes the preferences of the domestic stakeholders into account is much more successful. The forecasts of the NBS without constraints are quite similar. To commit oneself to a specific stance seems thus only to make a marginal difference. In the following sections we will analyse whether the Schelling conjecture has an empirical relevance to the average legislative decision within the European Union.

\subsection{THE PREDICTIVE ACCURACY OF FOUR VERSIONS OF THE NASH BARGAINING SOLUTION}

This section evaluates whether or not the two-level versions of the NBS yield better forecasts than the NBS without constraints. We will also explore the reason why the accuracy of the forecasts differs from one issue to another. As the case studies suggest, the predictive accuracy differs among the classes of models. We will evaluate why and when this happens.

Although average measures can be misleading to some extent, we start the analysis by comparing the mean error of the models. It should be noted that the benchmark for predictions of the two-level NBS with threats are the forecasts that were obtained for the very same issues with alternative NBS models. We report thus in parentheses the corresponding NBS predictions.

The general result of our evaluation is that the move from the symmetrical NBS to more complicated models does not really pay off (see 
Table 6.2. Average predictive accuracy of the NBS models (average absolute error across issues)

\begin{tabular}{lccccc}
\hline \hline \multicolumn{1}{c}{ Model } & $\begin{array}{c}\text { All issues } \\
(n=162)\end{array}$ & $\begin{array}{c}\text { CNS } \\
\text { QMV } \\
(n=55)\end{array}$ & $\begin{array}{c}\text { CNS } \\
\text { unan. } \\
(n=39)\end{array}$ & $\begin{array}{c}\text { COD } \\
\text { QMV } \\
(n=56)\end{array}$ & $\begin{array}{c}\text { COD } \\
\text { unan. } \\
(n=12)\end{array}$ \\
\hline Median $^{a}$ & 27.21 & 30.55 & 17.83 & 30.38 & 27.58 \\
& $(28.04)$ & $(30.62)$ & $(21.03)$ & $(29.90)$ & $(31.75)$ \\
NBS model & 25.8 & 27.13 & 17.33 & 30.8 & 23.84 \\
$\begin{array}{l}\text { NBS institutional } \\
\text { constraints }\end{array}$ & 29.28 & 33.8 & 18.41 & 34.24 & 20.76 \\
$\begin{array}{l}\text { NBS instit. constraints } \\
\text { preferences }\end{array}$ & 25.76 & 27.08 & 19.27 & 30.04 & 20.81 \\
$\begin{array}{c}\text { Two level NBS } \\
\text { with threats }\end{array}$ & 25.58 & 21.9 & 24.2 & 50.0 & 4.94 \\
\hline \hline
\end{tabular}

Note: ${ }^{a}$ Median of the data version with imputed values (original median in brackets).

Table 6.2). The symmetrical Nash bargaining solution predicts better than the model with institutional constraints, whereas the model with institutional and preferential constraints is slightly better than the symmetrical one. This suggests that countries in which the preferences of government parties and the EU affairs committees do not coincide possess a slight bargaining advantage. The importance of the ideological constraint is rather surprising, given the fact that we measured it crudely on a left-right dimension only. Facing a powerful EU affairs committee back home does not, by contrast, make a government more successful in the negotiations within the Council of Ministers. Similarly, if a negotiator makes an explicit threat, it can also not move the outcome closer to its ideal point in comparison to the NBS. We should, however, add at this point that the active usage of such strategic means is rather rare.

A comparison of the accurate point predictions of the two-level models and the threat model shows that different measures of predictive accuracy can tell us different stories. In 39 of I 62 issues the symmetric Nash solution predicted the outcome exactly, this is the case for the twolevel models in 35 issues and for the threat model in three of the 30 cases.

If we soften the criterion of accurate point predictions to a prediction around five points plus or minus the actual outcome position, we find that the symmetrical NBS predicts the outcomes of 56 (34.6 per cent) issues correctly, the institutional NBS forecasts $5 \mathrm{I}$ (3I.5 per cent) issues 
correctly, and the model with institutional and preferential constraints only 57 ( 35.2 per cent) issues correctly. That means that the criterion of point predictions sheds a similar light on the predictive accuracy of the models

Next, we explore the conditions under which some models predict better than others using a multivariate OLS regression. In particular, we examine whether issue and proposal characteristics are key to understanding variation in the predictive accuracy of the models. One key explanatory variable that could play a role is the number of issues under contestation. The more dimensions a proposal has, the more difficult it generally is to forecast the outcome because the possibility of trading votes grows. A second variable that has to be considered is the variance in the preferences. We expect a higher variance to decrease the predictive accuracy of the models. Our measure is the standard deviation of the preferences. If the preference distribution is skewed, however, we expect that the outcome is easier to predict, because it will be closer to the larger coalition than to the smaller one. We include the skewedness of the preference distribution as an explanatory variable. A related factor is whether or not the preferences among the actors are polarised. We use the Herfindahl-Hirschman index of concentration to account for this influence. ${ }^{\mathrm{I} 5} \mathrm{~A}$ final consideration is whether or not the imputation method affects the predictions. The corresponding dummy variable accounts for all the cases in which we imputed the reference point.

Table 6.3 reports the results of the OLS regressions with the absolute issue level error as the dependent variable. Note that we do not report the impact that decision-making rules and the policy domains have on the predictive accuracy of the four models under evaluation (see additional tables at the end of this chapter). Nor do we include scale measures in the multivariate analyses, because we believe scale to be largely a consequence of the perceived nature of conflict, rather than of a pre-given conflict space.

The table shows that the number of issues does not significantly influence the dependent variable which is the distance between the prediction and the actual outcome for any of the models. The same holds true for the skewedness of the preference distribution. The variables that

I5 The Herfindahl-Hirschman $(\mathrm{HH})$ index of concentration equals the sum of the squares of each position's percentage share. The larger this index, the higher the concentration of positions. See Ray and Singer (I990) for a political science application. 
Table 6.3. Determinants of the predictive accuracy of four NBS models

\begin{tabular}{lccccc}
\hline \hline & Median & $\begin{array}{c}\text { Symmetric } \\
\text { NBS }\end{array}$ & $\begin{array}{c}\text { Institutional } \\
\text { constraint } \\
\text { NBS }\end{array}$ & $\begin{array}{c}\text { Institutional } \\
\text { preference con- } \\
\text { straint NBS }\end{array}$ & $\begin{array}{c}\text { Threat } \\
\text { constraint } \\
\text { NBS }\end{array}$ \\
\hline $\begin{array}{l}\text { Number of } \\
\text { issues }\end{array}$ & 1.38 & 0.01 & 0.02 & 0.02 & -0.04 \\
$\begin{array}{l}\text { Standard } \\
\quad \text { deviation }\end{array}$ & $0.92^{a}$ & $0.01^{a}$ & $0.01^{a}$ & $0.01^{a}$ & 0.01 \\
$\begin{array}{l}\text { Skewedness } \\
\text { Concentration }\end{array}$ & 0.95 & 0.01 & 0.01 & 0.01 & 0.08 \\
$\begin{array}{l}\text { Imputed } \\
\quad-16.47\end{array}$ & $-10.11^{c}$ & $-0.21^{b}$ & 0.17 & $0.23^{b}$ & 0.37 \\
$\quad$ reference & & -0.09 & $-0.13^{b}$ & 0.13 \\
$\quad$ point & & & & & \\
$\begin{array}{l}\text { Constant } \\
n\end{array}$ & -14.20 & -0.16 & $-0.25^{b}$ & $-0.17^{c}$ & -0.14 \\
Adj. R Square & 0.10 & 162 & 162 & 162 & 30 \\
\hline \hline
\end{tabular}

Notes: ${ }^{a}$ significant at a $0.0 \mathrm{I}$ level.

$b$ significant at a 0.05 level.

${ }^{c}$ significant at a 0.10 level.

take the variance and the polarisation of the ideal points into account, conversely, have a significant impact on the accuracy of our predictions. The standard deviation exerts a significant influence in all models except the threat model. We measure the polarisation of preference through the Herfindahl-Hirschmann index, which is an instrument widely used to assess different forms of concentration. Note that this concentration measure differs considerably from the skewedness variable. The correlation coefficient between the two measures only amounts to- Quite remarkably, the concentration measure is significant for nearly all models and accounts for the largest part of the adjusted $\mathrm{R}^{2}$. As the case study already indicated, a high degree of polarisation worsens the accuracy of the model predictions. If the number of powerful factions decreases, the outcome is more likely to shift radically, increasing the error in the model predictions. The cases in which we imputed the reference point provide better forecasts than the ones where such an imputation was not necessary. Because we imputed the reference point through the position of the Commission, this result indicates once again how important the formal and informal agenda setting by this actor is. 


\subsection{CONCLUSION}

Interstate bargaining in the European Union is often seen as a form of interaction where the domestic constraints negotiators face back home prevent cooperation-minded governments from concluding far-reaching agreements. Illustrative evidence from the meetings of the European Council and the Council of Ministers support the contention that meetings within the European Union are affected strongly by the strategic moves of laggard governments. At the moment, all the evidence that we possess on EU negotiations is, however, largely descriptive and not based on any systematic comparative assessment.

This chapter has moved closer toward a systematic examination of EU negotiation processes. We have analysed whether domestic constraints influence the process of legislative bargaining in the European Union. Our analysis adds to a still-growing literature, that has up to now largely focused on the influence of domestic constraints on purely intergovernmental bargains within the European Union (Schneider and Cederman I994; König and Hug 2000; Hug and König 2002). In particular, we explore the impact that the European affairs committees in the national legislatures have on the negotiation behaviour of their ministers. We can show that governments can profit to some extent at the international level if the preferences of the domestic actors differ substantially. Our application also demonstrates that the NBS is a largely under-exploited tool to explain decision-making in the European Union. While it does not account for institutional factors, it yields reasonable forecasts based on a firm axiomatic foundation. Although its static nature and the reliance on cooperative considerations could be seen as a drawback, it is relatively easily tested and parsimonious compared with competing bargaining models. Future applications will compare its predictive accuracy with other bargaining models.

Yet, it has to be admitted that the differences in the predictive accuracy of the baseline NBS model and the two-level versions of the NBS are not large. This underlines, in agreement with the early descriptive literature and the contribution by Hammond and Prins (1999), that the active usage of domestic constraints as a bargaining mechanism is probably an infrequent event and restricted to high-stake negotiations. In day-to-day policy-making within the European Union, such events are obviously rare. The practical implication of our results is that domestic control mechanisms do not really function. Governments often strike deals in Brussels irrespective of the demands of the domestic stakeholders. This 
Table 6.4. Average absolute error across policy areas

\begin{tabular}{|c|c|c|c|}
\hline Model & $\begin{array}{l}\text { Agriculture } \\
(n=40)\end{array}$ & $\begin{array}{l}\text { Internal market } \\
\quad(\max n=34)\end{array}$ & $\begin{array}{l}\text { Other policy } \\
\text { areas }(n=88)\end{array}$ \\
\hline $\operatorname{Median}^{a}$ & $\begin{array}{c}29.85 \\
(=33.29)\end{array}$ & $\begin{array}{c}34.68 \\
(=39.60)\end{array}$ & $\begin{array}{l}23.13 \\
(29.13)\end{array}$ \\
\hline NBS model & 28.19 & 35.34 & 21.02 \\
\hline $\begin{array}{l}\text { Two-level NBS with institutional } \\
\text { constraints }\end{array}$ & 36.86 & 39.22 & 22.0 \\
\hline $\begin{array}{l}\text { Two-level NBS with institutional } \\
\text { and preferential constraints }\end{array}$ & 27.90 & 33.44 & 21.82 \\
\hline Two-level NBS with threats & $\begin{array}{c}30.0 \\
(n=4)\end{array}$ & $\begin{array}{l}4.94 \\
(n=3)\end{array}$ & $\begin{array}{l}27.50 \\
(n=23)\end{array}$ \\
\hline
\end{tabular}

Note: ${ }^{a}$ Median of the data version with imputed values (original median in brackets).

Table 6.5. Average absolute error across issues

\begin{tabular}{lccc}
\hline \hline \multicolumn{1}{c}{ Model } & $\begin{array}{c}\text { Dichotomous } \\
(n=33)\end{array}$ & $\begin{array}{c}\text { Rank order } \\
(n=109)\end{array}$ & $\begin{array}{c}\text { Scale } \\
(n=20)\end{array}$ \\
\hline Median $^{a}$ & 31.82 & 27.34 & 18.9 \\
& $(=30.30)$ & $(=29.42)$ & $(=19.7)$ \\
NBS model & 31.02 & 25.6 & 18.24 \\
$\begin{array}{l}\text { Two-level NBS with institutional } \\
\quad \text { constraints }\end{array}$ & 38.13 & 26.63 & 29.13 \\
$\begin{array}{l}\text { Two-level NBS with institutional and } \\
\text { preferential constraints }\end{array}$ & 31.37 & 25.3 & 19.03 \\
Two-level NBS with threats & 50.0 & 24.49 & 1.4 \\
& $(n=4)$ & $(n=23)$ & $(n=3)$ \\
\hline \hline
\end{tabular}

Note: ${ }^{a}$ Median of the data version with imputed values (original median in brackets).

problem will persist as long as ministers are able to mask their behaviour in Brussels. Our analysis thus reveals an important aspect of the 'democratic deficit' that could be easily solved by increasing the transparency of decision-making in the Council of Ministers. We have only little hope that the enlargement process has increased the quality of decisionmaking in the Council. Extensions of our research show unambiguously that preference distributions have become more polarised and that producer interests are the main winners in the legislation arena of the EU (Dobbins et al 2004; Zimmer et al 2005). The increased importance of 
protectionist and structurally conservative forces increases the incentive for governments to shield their behaviour in Brussels against domestic public scrutiny. Institutional reforms could alleviate this problem. Yet, the current wave of euroscepticism makes it highly unlikely that the European Union will adopt convincing decision-making rules in the near future. 